\title{
Radiolysis of C5-BTBP in cyclohexanone irradiated in the absence and presence of an aqueous phase
}

\author{
By A. Fermvik ${ }^{1,2, *}$, E. Aneheim ${ }^{1,2}$, B. Grüner ${ }^{3}$, Z. Hájková ${ }^{3}$, M. Kvíčalová1,2 and C. Ekberg ${ }^{1,2}$ \\ ${ }^{1}$ Nuclear Chemistry, Department of Chemical and Biological Engineering, Chalmers University of Technology, Kemivägen 4, 41296 Göteborg, \\ Sweden \\ 2 Industrial Materials Recycling, Department of Chemical and Biological Engineering, Chalmers University of Technology, Kemivägen 4, \\ 41296 Göteborg, Sweden \\ ${ }^{3}$ Institute of Inorganic Chemistry, v.v.i., Academy of Sciences of the Czech Republic, Řež near Prague 1001, Husinec-Řež 25068, \\ Czech Republic
}

(Received April 28, 2011, accepted in revised form: August 31, 2011)

(Published online March 12, 2012)

\section{Radiolysis / Degradation product / Solvent extraction / Partitioning / BTBP / Actinide / Lanthanide / Diluent}

Summary. Spent nuclear fuel contains many highly radioactive species; hence solvents used in reprocessing will be subjected to radiolysis. In this study, solvents containing one of the BTBP molecules intended for the separation of trivalent actinides and lanthanides, the so called C5-BTBP, have been subjected to radiolysis and hydrolysis. We present here that this compound shows a dramatic decrease in both distribution ratios and separation factor when irradiated with higher doses up to $50 \mathrm{kGy}$; particularly in the presence of an aqueous phase. Furthermore, fast hydrolytic degradation is observed, which significantly contributes to the overall degree of decomposition. This is supported by speciation studies performed by HPLC and LC-MS methods. Proposed structures of the highest-yield degradation products are presented and they seem to confirm previously drawn structures for these products. From these studies it can be concluded that the presence of nitric acid or nitrate during irradiation leads to higher content of species containing keto groups.

\section{Introduction}

Reprocessing of spent nuclear fuel may include many different separation processes. The current reprocessing technology, used in the PUREX (Plutonium Uranium Redox EXtraction) process, is based on a hydrometallurgical process (liquid-liquid extraction). In addition to uranium (U) and plutonium $(\mathrm{Pu})$ other elements can also be reprocessed. Most partitioning processes for this extended reprocessing rely on 1) co-extraction of trivalent actinides (An) and lanthanides (Ln) from PUREX raffinate, 2) selective actinide extraction for the An/Ln separation, 3) possibly americium/curium $(\mathrm{Am} / \mathrm{Cm})$ separation. Common for all processes is that they will be subjected to irradiation from the highly radioactive species present in the fuel. Therefore the phases used in such a liquid-liquid extraction process must be resistant towards radiolytic degradation.

\footnotetext{
*Author for correspondence (E-mail: anna.fermvik@mail.com).
}

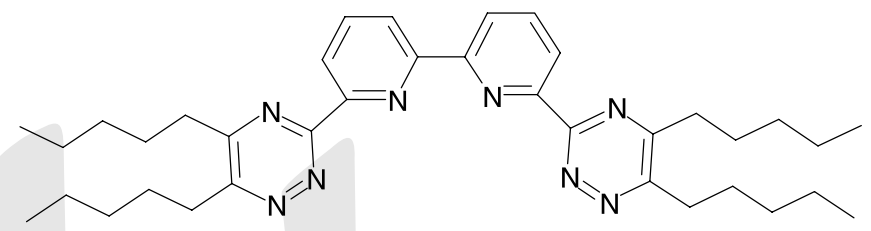

Fig. 1. Schematic picture of 6,6'-bis(5,6-dipentyl-[1,2,4]triazine-3-yl)[2,2']bipyridine (C5-BTBP) [6].

Trivalent actinides and trivalent lanthanides have similar chemical properties and this complicates the separation of these two groups of elements. One suggested process is SANEX (Selective ActiNide EXtraction) [1]. The BTBP (6,6'-bis(5,6-dialkyl-[1,2,4]triazine-3-yl)-[2,2' ]bipyridine) molecules were developed to selectively extract trivalent An from an aqueous phase using liquid-liquid extraction [2,3]. As opposed to many of its precursors, the BTBP molecule could effectively extract actinides without the use of a synergist [4]. The complexation was however not too strong, thus also enabling stripping of selected elements [5]. One BTBP molecule, C5-BTBP (6,6'-bis(5,6-dipentyl-[1,2,4]triazine3-yl)-[2,2']bipyridine) [6] see Fig. 1, showed promising distribution ratios and separation factors but it proved to lack radiolytic stability [5-7]. Irradiation of an organic solvent containing C5-BTBP leads to a decrease in extraction, thus rendering it useless for industrial applications. However, the radiolytic behaviour of C5-BTBP has been further studied in order to obtain useful knowledge about radiolytic degradation of BTBP molecules and about its degradation products $[8,9]$.

Previous radiolysis studies of C5-BTBP have been conducted by irradiating the organic phase alone, and then contacting this with an aqueous phase during extraction experiments. This gives useful basic information but does not provide insight into the whole complexity of the actions occurring in an industrial extraction process when both irradiation and long-term contact with an aqueous phase simultaneously contribute to the extractant degradation. Thus, knowledge about the radiolytic behavior of an organic phase irradiated in the presence of an aqueous phase is desirable. 
Water radiolysis yields many highly reactive species [10] that can react with the BTBP in the organic phase. In addition, contact with an aqueous phase can result in hydrolysis, which may further degrade BTBP and affect the extraction behavior. Hydrolysis of C5-BTBP has previously not been studied in detail.

In two previous papers $[8,9]$ irradiated solvents containing C5-BTBP in both hexanol and cyclohexanone were analyzed using ESI- (Electrospray Ionization-) and APCIMS (Atmospheric Pressure Chemical Ionization-Mass Spectrometry) as well as HPLC (High Performance Liquid Chromatography) and LC-MS (Liquid Chromatography-Mass Spectrometry), and structures of a number of degradation products were proposed. This paper presents an extension of these studies, using higher applied doses and more importantly; the organic phases were in permanent contact or saturated with aqueous phase before irradiation. Use of recently developed HPLC and LC-MS separations [9] allowed for quantification of the initial compound and semi-quantitative estimate of concentration of the decomposition products. We present here also details on hydrolysis of the C5-BTBP in cyclohexanone in contact with two aqueous phases completed with degradation products speciation, including new findings. Hydrolysis significantly contributes to the overall decomposition pathways and to the sample ageing. This study thus represents a more detailed insight into C5-BTBP decomposition, confirming and completing the validity of previous reports $[8,9]$.

\section{Theory}

Water radiolysis yields many highly reactive species, according to React. (R1). The highest yields are found for the hydroxyl radical, the solvated electron and the hydrogen ion [10].

$$
\mathrm{H}_{2} \mathrm{O}+\text { radiation } \rightarrow{ }^{\bullet} \mathrm{OH},{ }^{\bullet} \mathrm{H}, \mathrm{e}_{\mathrm{aq}}^{-}, \mathrm{H}_{2}, \mathrm{H}_{2} \mathrm{O}_{2}, \mathrm{H}^{+}
$$

The solvated electron is a powerful reducing agent but in process conditions involving an acidic environment, and in the presence of oxygen, the solvated electron is quickly scavenged via Reacts. (R2) and (R3) [10]:

$$
\begin{array}{ll}
\mathrm{e}_{\mathrm{aq}}^{-}+\mathrm{H}^{+} \rightarrow \cdot \mathrm{H} & k=2.3 \times 10^{10} \mathrm{M}^{-1} \mathrm{~s}^{-1} \\
\mathrm{e}_{\mathrm{aq}}^{-}+\mathrm{O}_{2} \rightarrow \mathrm{O}_{2}^{\circ-} & k=1.9 \times 10^{9} \mathrm{M}^{-1} \mathrm{~s}^{-1}
\end{array}
$$

It can also react with nitrate ions according to React. (R4) [10]:

$$
\mathrm{e}_{\mathrm{aq}}^{-}+\mathrm{NO}_{3}{ }^{-} \rightarrow \mathrm{NO}_{3}{ }^{2-} \quad k=9.7 \times 10^{9} \mathrm{M}^{-1} \mathrm{~s}^{-1}
$$

In water irradiated with low LET-radiation, the hydrogen atom radical accounts for about $10 \%$ of total free radical concentration [11]. The hydrogen radical reacts with organic compounds in two general ways; an addition reaction or hydrogen atom abstraction [11], but presence of dissolved oxygen scavenges the radicals [12]:

$$
\mathrm{H}^{\bullet}+\mathrm{O}_{2} \rightarrow \mathrm{HO}_{2}{ }^{--} \quad k=12.1 \times 10^{10} \mathrm{M}^{-1} \mathrm{~s}^{-1}
$$

The strongly oxidizing hydroxyl radical however, has few scavengers in an acidic solution and may combine to form hydrogen peroxide.
The aqueous phase in this study also yields additional radicals that are formed by the nitrate radiolysis (Reacts. R6-R8):

$$
\begin{aligned}
& \mathrm{NO}_{3}{ }^{-}+\text {radiation } \rightarrow \mathrm{e}_{\text {aq }}^{-}+{ }^{\bullet} \mathrm{NO}_{3}[13] \\
& \cdot \mathrm{NO}_{3}{ }^{2-}+\mathrm{H}_{2} \mathrm{O} \rightarrow{ }^{-} \mathrm{NO}_{2}+2 \mathrm{OH}^{-} \\
& k=5.5 \times 10^{4} \mathrm{M}^{-1} \mathrm{~s}^{-1} \text { [14] } \\
& \cdot \mathrm{NO}_{3}{ }^{2-}+\mathrm{H}^{+} \rightarrow \cdot \mathrm{NO}_{2}+\mathrm{OH}^{-} \\
& k=4.5 \times 10^{10} \mathrm{M}^{-1} \mathrm{~s}^{-1}[14]
\end{aligned}
$$

The probability of direct radiolysis of the nitrate anion is rather unlikely in the system used in this study, since the $\mathrm{NO}_{3}{ }^{-}$concentration in the aqueous phase is quite low $(1 \mathrm{M})$, compared to the water concentration.

The hydroxyl radical as well as the nitrogen-centered radicals resulting from Reacts. (R6)-(R8) can react further through for example hydrogen abstraction reaction $[11,15]$ with BTBP molecules. Other possible reactions are single electron transfer [11] or addition [15] to BTBP carbon radicals, hence forming nitrated derivatives of BTBP. A BTBP radical, formed for example via hydrogen atom abstraction, can then either fragment or react with yet another radical to get rid of its excess energy, e.g.:

$$
\mathrm{BBTBP}^{\bullet}+\mathrm{OH}^{\bullet} \rightarrow[\mathrm{BTBP}]-\mathrm{OH}
$$

\section{Experimental}

In all experiments the organic phase initially comprised $0.005 \mathrm{M}$ C5-BTBP in cyclohexanone while the aqueous phase constituted of $0.01 \mathrm{M} \mathrm{HNO}_{3}+0.99 \mathrm{M} \mathrm{NaNO}_{3}$ (pure water for one of the hydrolysis systems). For the extraction experiments, a stock solution containing traces of ${ }^{241} \mathrm{Am}$ and ${ }^{152} \mathrm{Eu}$ was added to the aqueous phase.

\subsection{Chemicals}

The following chemicals were used in the study: cyclohexanone (> 99.5\%, Sigma Aldrich), $\mathrm{HNO}_{3}$ (FIXANAL, Sigma Aldrich), $\mathrm{NaNO}_{3}(>99 \%$ pro analysi, Merck) and MQwater (Milli-Q gradient, Millipore ${ }^{\circledR},>18 \mathrm{M} \Omega$ ) acetonitrile (Gradient Grade, Aldrich). The spike solution containing americium $\left({ }^{241} \mathrm{Am}\right)$ and europium $\left({ }^{152} \mathrm{Eu}\right)$ was prepared from laboratory stock solutions [7] and contained approximately $2 \mathrm{MBq} / \mathrm{mL}{ }^{241} \mathrm{Am}$ and $0.2 \mathrm{MBq} / \mathrm{mL}^{152} \mathrm{Eu}$. C5-BTBP was synthesized according to [6], using commercially available chemicals of analytical grade.

\subsection{Irradiation}

A solvent containing $0.005 \mathrm{M}$ C5-BTBP in cyclohexanone was irradiated in a ${ }^{60} \mathrm{Co}$ source under three different conditions:

1. Irradiation of organic phase alone

(Series 1)

2. Irradiation of organic phase pre-equilibrated with aqueous phase

(Series 2)

3. Irradiation of organic and aqueous phase in contact

(Series 3) 
The aqueous phase contained $0.01 \mathrm{M} \mathrm{HNO}_{3}+0.99 \mathrm{M}$ $\mathrm{NaNO}_{3}$. Solvents to be irradiated were placed in $6 \mathrm{~mL}$ glass bottles and sealed with lids. Series 1 constituted of six bottles, each containing $2 \mathrm{~mL}$ of pure organic phase. Series 2 and 3 constituted of the same number of bottles but containing $2 \mathrm{~mL}$ pre-equilibrated organic phase and $2 \mathrm{~mL}$ organic + $2 \mathrm{~mL}$ aqueous phase, respectively.

All samples were irradiated by $\gamma$ rays in a ${ }^{60} \mathrm{Co}$ source (located at ICHTJ (Instytut Chemii i Techniki Jadrowej) in Warsaw, Poland) with a dose rate of $0.939 \mathrm{kGy} / \mathrm{h}$. Bottles were placed in the source at various times and all removed at the same time, resulting in doses between 5 and $50 \mathrm{kGy}$. This procedure was chosen to avoid different time intervals between end of irradiation and extraction experiments. Corresponding samples were kept outside the irradiator to act as reference samples. Since C5-BTBP is not stable with time [16], all bottles were kept in a freezer $\left(-35^{\circ} \mathrm{C}\right)$ before and after irradiation. Such conditions are known from earlier experiments to prevent the aging of the samples and their further decomposition [17].

\subsection{Hydrolytic stability}

A stock solution of $0.005 \mathrm{M}$ C5-BTBP in cyclohexanone $(25 \mathrm{~mL})$ was prepared. $4 \mathrm{~mL}$ of the organic phase was put into contact with equal volume of two different aqueous phases in glass tubes with polypropylene stoppers according to the following:

\section{Organic phase in contact with $0.01 \mathrm{M} \mathrm{HNO}_{3}$ $+0.99 \mathrm{M} \mathrm{NaNO}_{3}$}

(System X)

Y. Organic phase in contact with $\mathrm{H}_{2} \mathrm{O}$

(System Y)

The test tubes were shaken continuously on a Heindolph Multi Reax shaker at $1200 \mathrm{rpm}$ for $10 \mathrm{~d}$ and thereafter they were shaken for two hours a day. Two samples of $50 \mu \mathrm{L}$ of the organic phase were taken after $1,3,5,7,24,30 \mathrm{~h}$ and after $2,3,4,5,6,7,8,10,14,22$ and $30 \mathrm{~d}$ (when the C5-BTBP had completely disappeared). The samples were diluted with acetonitrile $(950 \mu \mathrm{L})$ and measured by HPLC- Method I (see below) to determine the concentration of remaining C5-BTBP. The data presented correspond to an average from two injections made for each sample, i.e. from four analyses for each point. Peak areas corresponding to the respective peaks on the HPLC chromatograms (UV detection) are given and demonstrate the formation of decomposition products over time in the system and otherwise only have semi-quantitative character. The identity of the components was assigned from comparison of HPLC chromatograms with MS and LC-MS (APCI ${ }^{+}$ion current detection) results, which served for peak identification.

\subsection{Extraction experiments}

All extraction experiments were performed at the same time and the procedure was as follows: $250 \mu \mathrm{L}$ organic phase (irradiated or non-irradiated solvent), $240 \mu \mathrm{L}$ aqueous phase and $10 \mu \mathrm{L}$ spike solution was contacted in $3.5 \mathrm{~mL}$ glass vials. The samples were shaken during $40 \mathrm{~min}$ in a shaking device. This time has proven to be sufficient to reach equilibrium for the system. Samples were then centrifuged to ensure complete phase separation and aliquots of $100 \mu \mathrm{L}$ were then taken from each phase and measured with a high purity germanium detector (Ortec Gamma Analyst GEM 23195). The $\gamma$-peaks at 59.5 and $121.8 \mathrm{keV}$ were examined for ${ }^{241} \mathrm{Am}$ and ${ }^{152} \mathrm{Eu}$, respectively, and the distribution ratio $(D)$ was calculated as the ratio between the count rate in the organic phase and the aqueous phase. Uncertainties were based on error propagation from measurement statistics.

There is a mutual solubility between water and cyclohexanone $(2.3 \mathrm{wt}$. \% cyclohexanone in water, $8 \mathrm{wt}$. \% water in cyclohexanone) [18] so the pre-equilibration of phases before contact might be of importance. For the system in this study, C5-BTBP in cyclohexanone and a weak acid as aqueous phase, it has previously been reported that a preequilibrated system gives the same distribution ratios as a non pre-equilibrated system [19]. To confirm this, extraction experiments were carried out both with and without pre-equilibration of the solvent that was irradiated alone (Series 1). For the solvent that had been irradiated in the presence of an aqueous phase (Series 3), extraction experiments were performed both with the irradiated aqueous phase and with a fresh aqueous phase, to see if it had any effect on the distribution ratios.

\subsection{HPLC, LC-MS and MS-analyses}

Analyses were performed using basically the methods developed and described in a previous paper [9]. Uncertainties were based on an estimation of the uncertainties connected to the analysis (from injection statistics) and the sample preparation.

\subsection{System used for quantitative/semi-quantitative HPLC analyses using DAD detection}

Samples were analyzed on HPLC system LaChrom series 7000, Merck-Hitachi equipped with L-7001 Series HPLC pump, L-7250 Intelligant Autosampler, L-7450 Diode Array detector, D-7000 Interface and HPLC System Manager D-7000. The chromatographic conditions and experimental details are given in a previous paper [9]. The calibration curve was linear in the whole range, $R^{2}=0.9944$.

\subsection{MS and LC-MS instrumentation for compound's identification}

The mass spectral data were acquired on a LCQ Fleet ion trap mass spectrometer, Thermo Finnigan (San Jose, CA, USA) equipped with an APCI interface operated in the positive-ion mode. Nitrogen was used as auxiliary and sheath gas and the collision gas in the ion trap was helium. For analyses of all samples APCI ion source in positive mode was used. The conditions used for APCI interface are the same as given in a previous paper [9], the only difference being the mass range for the LC-MS measurements, which was $80-1000$ in this latest study.

Considering the semi-quantitative estimate of the degradation products concentrations, the sum of the peak areas from HPLC chromatograms measured at 235 and $237 \mathrm{~nm}$ remained approximately constant, excluding a solvent peak up to approx. $3.5 \mathrm{~min}$. and with only exception for the deeply 
decomposed samples. From this (along with similar structures and UV-DAD spectra of the identified components) it was concluded that the percentage of peak areas of the decomposition products would closely correspond to their real presence in the system.

\section{Results}

\subsection{Hydrolysis}

As expected, C5-BTBP is clearly susceptible to hydrolysis and the concentration of BTBP is decreasing with the time spent in contact with aqueous solution. Fig. 2 illustrates the decrease in concentration, determined by HPLC and LCMS, for the two different conditions described as System $\mathrm{X}$ and $\mathrm{Y}$ above $\left(\mathrm{X}\right.$ - contact with $0.01 \mathrm{M} \mathrm{HNO}_{3}+0.99 \mathrm{M}$ $\mathrm{NaNO}_{3}, \mathrm{Y}$ - contact with $\mathrm{H}_{2} \mathrm{O}$ ). Comparatively fast rates of degradation were observed for both systems. About 50\% of the initial C5-BTBP had degraded after approx. 10 and $7 \mathrm{~d}$ for the two systems, respectively, and after $30 \mathrm{~d}$ all C5BTBP had decomposed in both systems. C5-BTBP has also been reported to somewhat degrade with time $[8,16]$. This change, expressed as decrease in distribution ratio, is however not at all as large as the change in the hydrolysis samples. For example, $D_{\mathrm{Am}}$ was unchanged for a solution left in room temperature for three days and after $30 \mathrm{~d}$ (when the hydrolysis study showed no presence of C5-BTBP) the $D_{\mathrm{Am}}$ had decreased to $60 \%$ of the initial value [16]. In a solution that was aged for six months, presence of two degradation products were found (compound $\mathrm{A}$ and $\mathrm{C}$ in Table 1) and the amount of C5-BTBP had decreased but was still higher than the amount of each of the degradation products [8]. The longest irradiations in this study took $53 \mathrm{~h}$, thus it is assumed that no ageing occurred during that period and the degradation is a result of hydrolysis and radiolysis. For the hydrolysis study however, ageing is certainly contributing to the degradation in the later part of the study, but it does not account for the whole decrease in concentration. Hence, when evaluating Fig. 2, it should only be concluded that C5$\mathrm{BTBP}$ is prone to hydrolysis, no exact rate should be given at

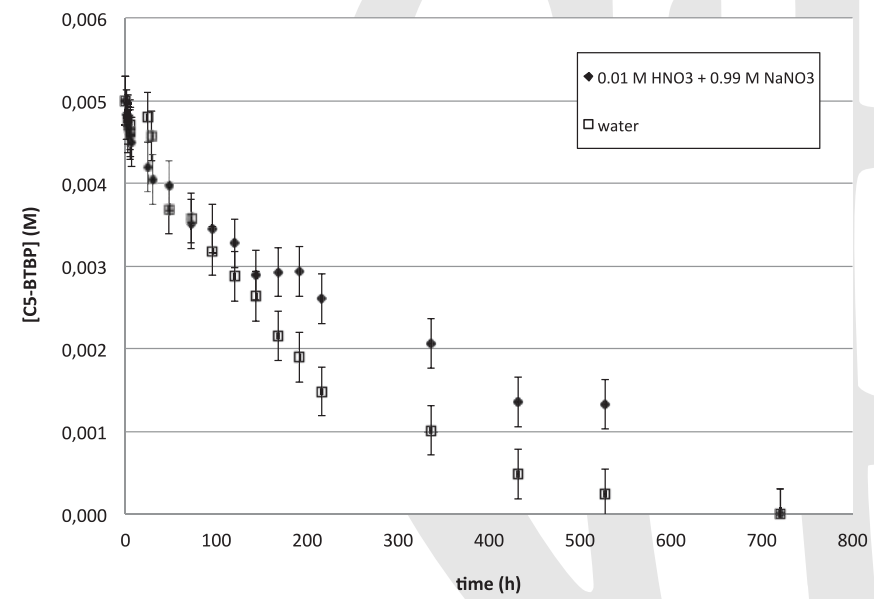

Fig. 2. Decrease in concentration of the C5-BTBP molecule dissolved in cyclohexanone and in contact with $0.01 \mathrm{M} \mathrm{HNO}_{3}+0.99 \mathrm{M} \mathrm{NaNO}_{3}$ (System X) or water (System Y), determined by HPLC. Uncertainties are based on an estimation of the uncertainties connected to the analysis (from injection statistics) and the sample preparation. this point. A study looking at the degradation due to ageing alone is in progress.

The rate of hydrolysis in both systems was similar from the beginning up to approx. the $7^{\text {th }}$ day $(\sim 170 \mathrm{~h})$, but was thereafter slightly slower for System X. Thus, the hydrolysis seems to be somewhat higher in presence of pure water than in presence of nitric acid/sodium nitrate aqueous phase. One explanation to this could be that the presence of nitric acid/sodium nitrate induces a decrease in water activity, hence also decreasing the water concentration in the organic phase.

From these results it is clear that hydrolysis gives an important contribution to the decomposition rate of C5-BTBP irradiated in the presence of an aqueous phase.

\subsection{Radiolysis}

The irradiated samples were studied both in terms of change in C5-BTBP concentration and change in extracting behavior.

In Fig. $3 D_{\mathrm{Am}}$ is plotted as a function of the received dose for the three series (1-3). The two sets of extraction experiments with Series 1 (with and without pre-equilibration) showed similar distribution ratios, hence confirming that the choice to pre-equilibrate or not have no effect on the values of extraction for this system. Thus, the distribution ratios plotted for Series 1 are average values of extraction experiments both with and without pre-equilibration. Series 3 gave similar distribution ratios whether the irradiated aqueous phase was used or if it was replaced with a fresh preequilibrated solution. Plotted values for Series 3 are thus average values of the experiments with irradiated and fresh aqueous phase, respectively.

It is clear that the presence of an aqueous solution, either dissolved in the organic phase or present as a separate aqueous phase (although still partly dissolved in the organic phase), enhances the decrease in $D_{\mathrm{Am}}$ with dose. For the organic phase that was irradiated alone, the $D_{\mathrm{Am}}$ decreases to around $40 \%$ of the start value $\left(D_{\mathrm{Am}}=23\right)$ after a dose of $50 \mathrm{kGy}$, while the other two series reach levels as low as $10 \%$ of the initial value $\left(D_{\mathrm{Am}}=21-26\right)$. The initial values are based on samples of solvent that, apart from not being irradiated, was treated in the same way as the irradiated samples in terms of storage time and temperature. Thus, the possible effect of ageing can be assumed to be the same for all samples, since they were prepared at the same time, stored in similar manner, and extraction experiments performed at the same time.

There is little difference in values between Series 2 and 3 , suggesting that the amount of aqueous phase dissolved in pre-equilibrated solvent is enough to cause the decrease in $D_{\text {Am }}$, compared to the irradiated pure organic phase.

Distribution ratios for Eu were also decreasing with dose, and the pattern was the same as for Am; the solvents with aqueous phase present gave a larger decrease. For all three solvents, the distribution ratio for Eu did not decrease to the same extent as it did for Am. This behavior results in a decreasing separation factor between the elements $\left(\mathrm{SF}_{\mathrm{Am} / \mathrm{Eu}}\right)$, which is illustrated in Fig. 4 where the change in $\mathrm{SF}_{\mathrm{Am} / \mathrm{Eu}}$ is plotted as a function of the dose for all three solvents (Series 1-3). The increase in $\mathrm{SF}_{\mathrm{Am} / \mathrm{Eu}}$ after $20 \mathrm{kGy}$ is an unlikely 


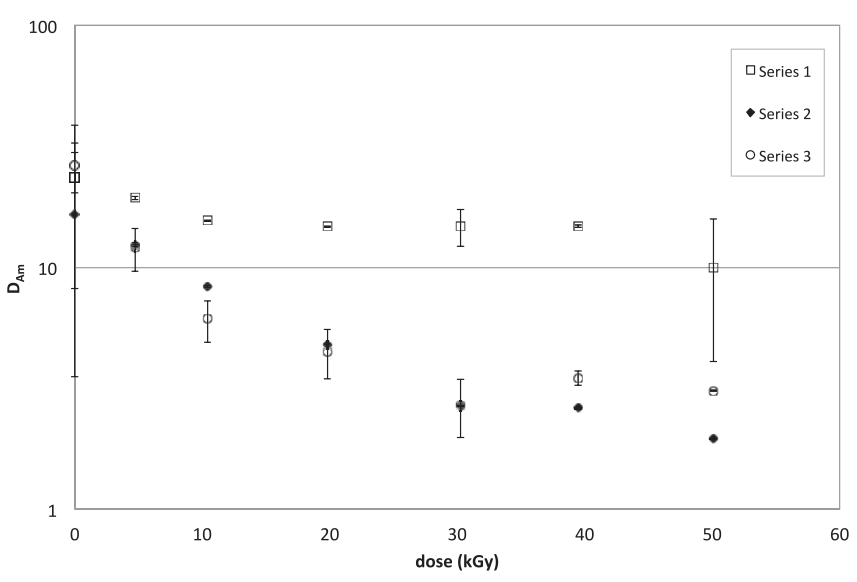

Fig. 3. Distribution ratio of americium as a function of the received dose for three similar organic solvents irradiated under different conditions.

behavior that has not been observed for this system before. However, there were large deviations and consequently large uncertainties for many of the extraction experiments. Thus, Fig. 4 below should only serve as an indication of the general trend, i.e. a $\mathrm{SF}_{\mathrm{Am} / \mathrm{Eu}}$ that decreases with dose, the decrease being larger when an aqueous phase is present during irradiation.

Series 2 and 3 (pre-equilibrated and in contact), showed a larger decrease in $\mathrm{SF}_{\mathrm{Am} / \mathrm{Eu}}$ than the solvent that was irradiated in the absence of any aqueous phase. $\mathrm{SF}_{\mathrm{Am} / \mathrm{Eu}}$ decreased to around 20 and $30 \%$ of the reference value for Series 2 and 3 , respectively. The similar dose $(50 \mathrm{kGy})$ yielded a decrease to around $65 \%$ of the reference value for Series 1 . Thus, the presence of aqueous phase during irradiation causes both lower extraction capacity and lower selectivity of the solvent compared to if the organic phase is irradiated alone. It has previously been suggested that the degradation products have a lower selectivity for An over $\operatorname{Ln}[8,9]$, hence a higher degree of degradation also leads to lower $\mathrm{SF}_{\mathrm{An} / \mathrm{Ln}}$.

The concentration of C5-BTBP in irradiated samples is clearly decreasing with dose. As could be expected from the extraction results, together with the hydrolysis results, the decrease is much more marked when aqueous phase was present during irradiation, either in permanent contact (Series 3) or dissolved in pre-equilibrated organic phase (Se-

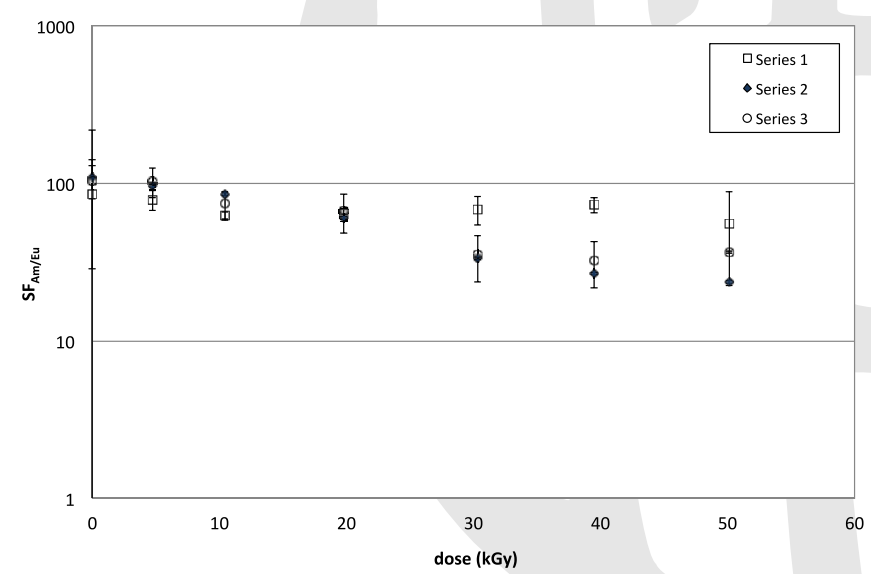

Fig. 4. Separation factor between $\mathrm{Am}$ and $\mathrm{Eu}$ as a function of the received dose for three similar organic solvents irradiated under different conditions.

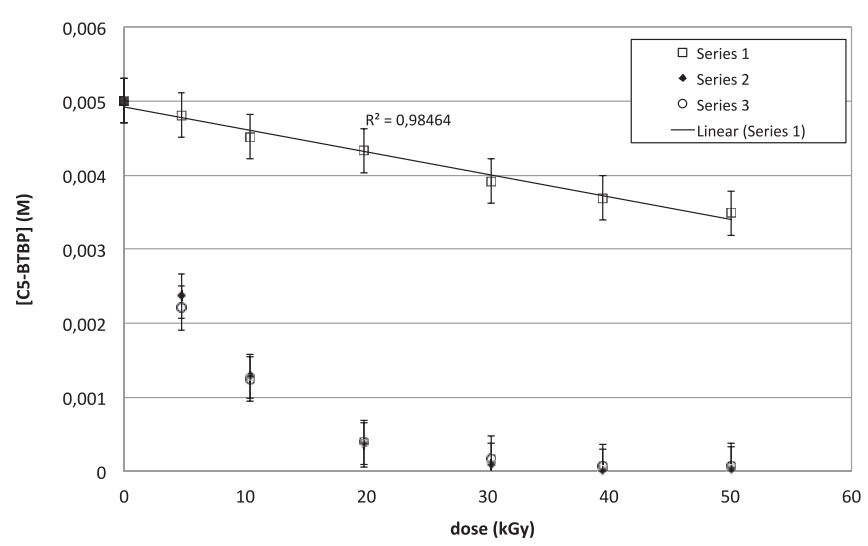

Fig. 5. Concentration of the original molecule C5-BTBP as function of the received dose for three similar organic solvents irradiated under different condition. Concentrations determined with HPLC.

ries 2). This is illustrated in Fig. 5, which shows the concentration change with increased dose. The curves for Series 2 and 3 are very similar and it cannot be said that one decreases more than the other. For Series 1, the decrease seems to more or less follow a straight line, and a linear fit of the curve gives an initial $G$-value of $0.0304 \mu \mathrm{M} / \mathrm{J}$ $\left(R^{2}=0.9846\right)$. $G$ expresses the radiation chemical yield (or consumption), and is defined as the number of molecules transformed per absorbed amount of energy [20]. The initial $G$-value greatly increases with an aqueous phase present during irradiation. Based on the three first data points in each series the $G$-values for Series 2 and 3, respectively, are $0.3513 \mu \mathrm{M} / \mathrm{J}\left(R^{2}=0.9168\right)$ and $0.3548 \mu \mathrm{M} / \mathrm{J}\left(R^{2}=\right.$ $0.8954)$.

When comparing the results from the irradiation with the hydrolysis results it is very clear that the decrease in BTBP concentration due to hydrolysis does not account for the whole difference in BTBP degradation between irradiated neat solvent and solvent in contact with aqueous phase. In Fig. 6 the decrease in BTBP concentration as a function of time is plotted for the hydrolysis test (System X) as well as for the radiolysis tests (all three series). It is clear that hydrolysis only contributes to a small extent to the overall degradation of the molecule in these radiolysis experiments.

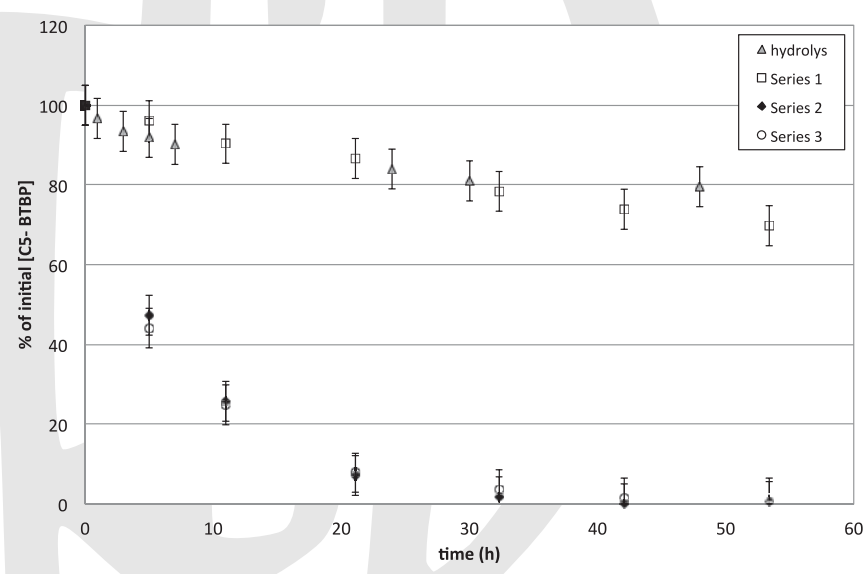

Fig. 6. Decrease in C5-BTBP concentration (as \% of initial value) for the hydrolysis and the radiolysis tests. The aqueous phase in all experiments comprised of $0.01 \mathrm{M} \mathrm{HNO}_{3}+0.99 \mathrm{M} \mathrm{NaNO}_{3}$. 
Table 1. Proposed structures for degradation products resulting from the irradiation of C5BTBP in cyclohexanone $[8,9]$.

Product $\mathrm{m} / \mathrm{z}$ Ratio
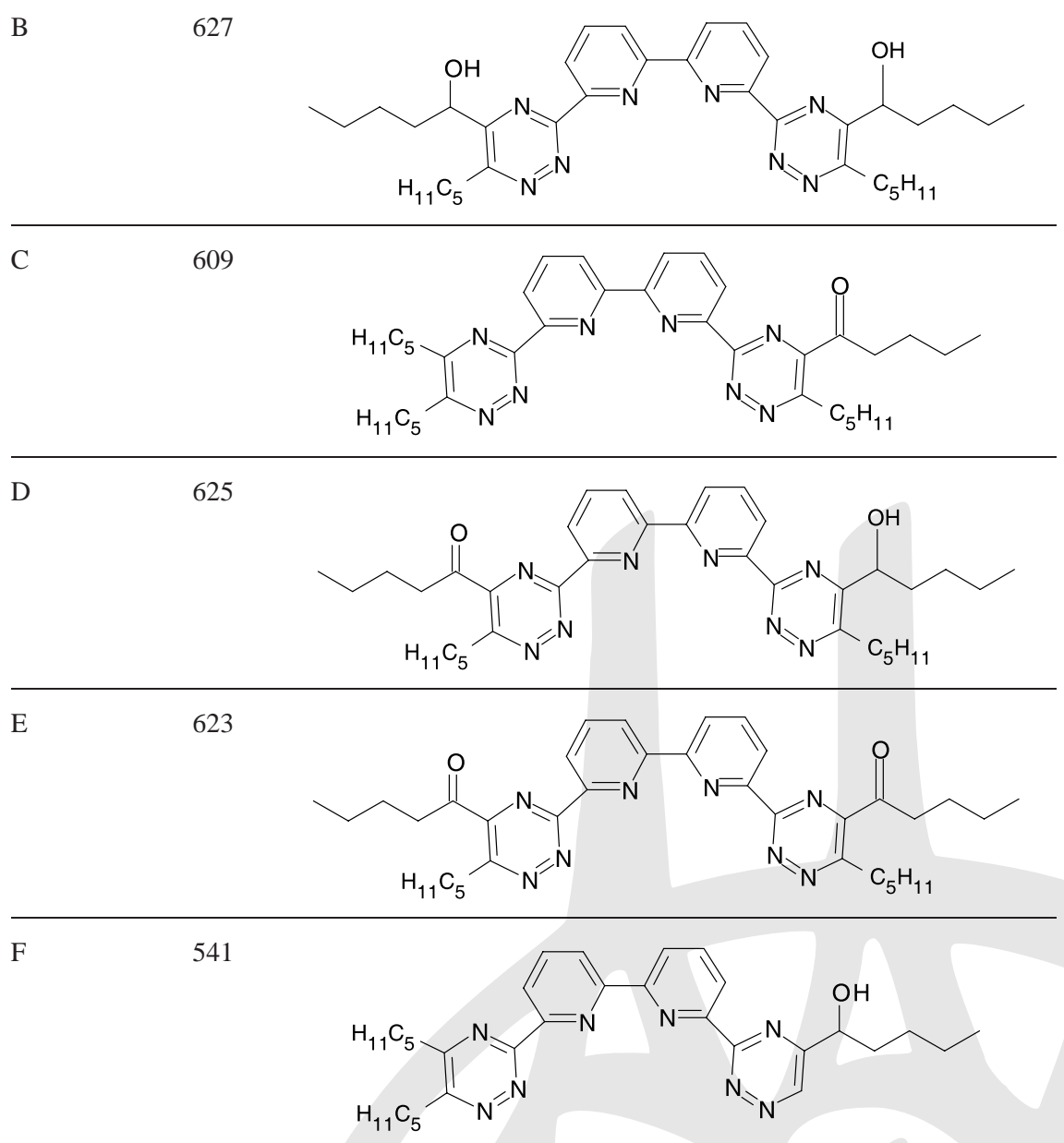

a: Compound B, D and E can be present as several positional isomers.

\subsection{Degradation products}

Table 1 illustrates the structure of the suggested degradation products $[8,9]$, together with their $m / z$ (mass to charge) ratio, that are discussed in this paper. The $m / z$ ratio for the original molecule is 595.5 .

As can be seen in the table, the degradation products are suggested to be hydroxyl or keto-substituted at the $\alpha$ $\mathrm{CH}_{2}$ position of the pentyl chain/chains. This was suggested since a similar behavior had previously been reported for radiolysis of $n$ Pr-BTP [21]. In a recent paper by Retegan et al. ESI-MS was used to confirm the instability of C5-BTBP at this position [22]. The hydroxyl and keto-derivatives can be the results of reactions initiated by hydrogen atom abstraction or ${ }^{\bullet} \mathrm{OH}$ radical addition. Radical attacks on a second $\alpha-\mathrm{CH}_{2}$ lead to degradation products with double functionalized groups, such as compound B, D and E in the table.
$\mathrm{CyMe}_{4}$-BTBP [6] is an extractant similar to C5-BTBP but with cyclohexyl rings instead of pentyl groups attached to the triazinyl rings, thus avoiding the weak point of the $\alpha$ $\mathrm{CH}_{2}$. This compound has shown a much higher stability, both regarding radiolysis and hydrolysis [7, 23].

Fig. 7 shows the chromatograms for the reference sample (no irradiation, no contact with aqueous phase) and the three samples irradiated with 5, 10 and $20 \mathrm{kGy}$ for all three solvents (Series 1-3). The last peak with the highest retention time ( $c$. $28 \mathrm{~min}$ ) represents the C5-BTBP molecule. HPLC and MS analyses of the sample irradiated in neat cyclohexanone (Series 1) revealed relatively lower degree of decomposition with formation of main degradation products containing hydroxy groups, mainly product A and B (see Table 1), which were identified in previous studies [8,9]. It is obvious how the peak of C5-BTBP decreases much more for Series 2 and 3 (middle and bottom figures). The chro- 

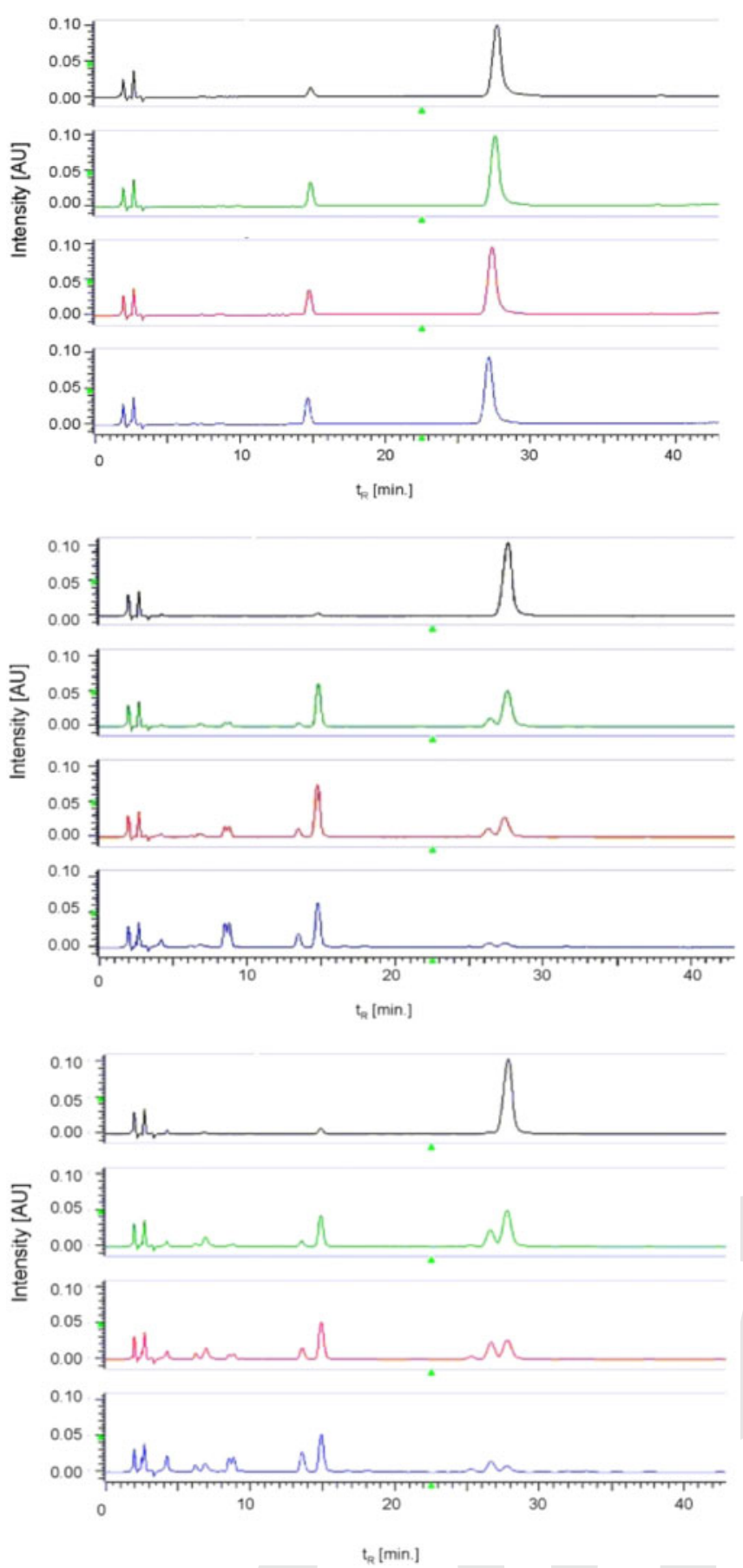

to compounds affected by higher degree of oxidation, containing the keto-groups in their structures (products $\mathrm{C}-\mathrm{E}$ in Table 1) or to a deeper decomposition (exemplified by compound $\mathrm{F}$ in Table 1). The latter species can be found at $c a$. 4-7 min., close to the start of the chromatograms.

Concentrations of the various degradation products were calculated based on semi-quantitative measurements where it was assumed that the total peak area corresponds to the initial concentration of C5-BTBP, i.e. $0.005 \mathrm{M}$. To be able to make reliable quantitative measurements pure samples of the degradation products are required, however these have not yet been available. In Figs. 8-10 below, the curves are there as means to guide the eye to the general trend of the results and do not reflect any modeling attempt.

Fig. 8 shows how the peak areas of two degradation products change in Series 1 as the solvent receives more and more dose. These were the only two degradation products found in the samples from Series 1 . The degradation product with $m / z=611$ (product A) corresponds to an oxidized form of C5-BTBP, with a hydroxyl group attached at the alpha carbon in one of the C5-chains. The other product (B) observed in Series 1 corresponds to a further oxidized form of C5-BTBP, with hydroxyl groups on two C5-chains $(m / z=627)$. It should be noted that two partly resolved peaks with $t_{\mathrm{R}}$ at 8.5 and $8.8 \mathrm{~min}$ (see chromatograms for Series 2 and 3 in Fig. 7), corresponding apparently two or more positional isomers, were integrated together. From structural considerations it follows that in principle, the $\mathrm{OH}$ groups can be situated either at the same triazinyl ring or on two opposite rings in syn (cis) or anti (trans) positions. However, from $\mathrm{ms} / \mathrm{ms}$ experiment it was not possible to distinguish between these possibilities. The concentration of both degradation products observed increases with dose, but product A reaches a much higher concentration than product $\mathrm{B}$. It has previously been shown that product A reaches a maximum and then the concentration starts to decrease; hence it is not stable towards radiolysis $[8,9]$.

Figs. 9 and 10 illustrate the growth of degradation products for Series 2 and 3, respectively. Note that the scales on the $y$-axes differ from the scale in Fig. 8. The additional peaks/degradation products observed in the solvents with aqueous phase present are referred to as $\mathrm{C}, \mathrm{D}, \mathrm{E}$ and $\mathrm{F}$ (see

Fig. 7. HPLC-chromatograms of samples from Series 1-3. The upper array of four chromatograms is for Series 1 , followed by Series 2 in the middle and Series 3 at the bottom. In each chromatogram the first sample is the reference sample (black line), and then the sample that received a dose of 5 (green line), 10 (red line) and $20 \mathrm{kGy}$ (blue line), respectively.

matograms for Series 2 and 3 at $20 \mathrm{kGy}$ show notably higher peaks of products A (peak around $15 \mathrm{~min}$ ) and B (two partly resolved peaks between 8.5 and $8.8 \mathrm{~min}$ ), but also substantial presence of other decomposition products that have been identified in previous studies $[8,9]$, but there only as really minor components. Some of the additional peaks are situated close to peaks of C5-BTBP and peaks of degradation products observed in previous irradiation studies [9], indicating structural similarity between the compounds. Indeed, as has been found by detailed MS and LC-MS studies of the samples, composition of these species can be ascribed

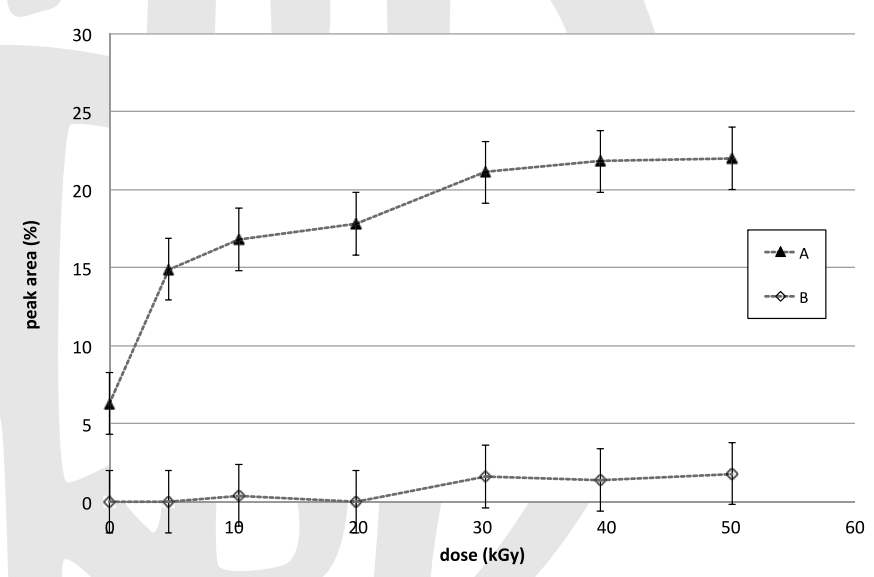

Fig. 8. Growth of degradation products with dose for an irradiated solvent containing C5-BTBP in cyclohexanone. Labels A and B refer to the structures given in Table 1. Concentrations determined with HPLC and components identified by LC-MS. 


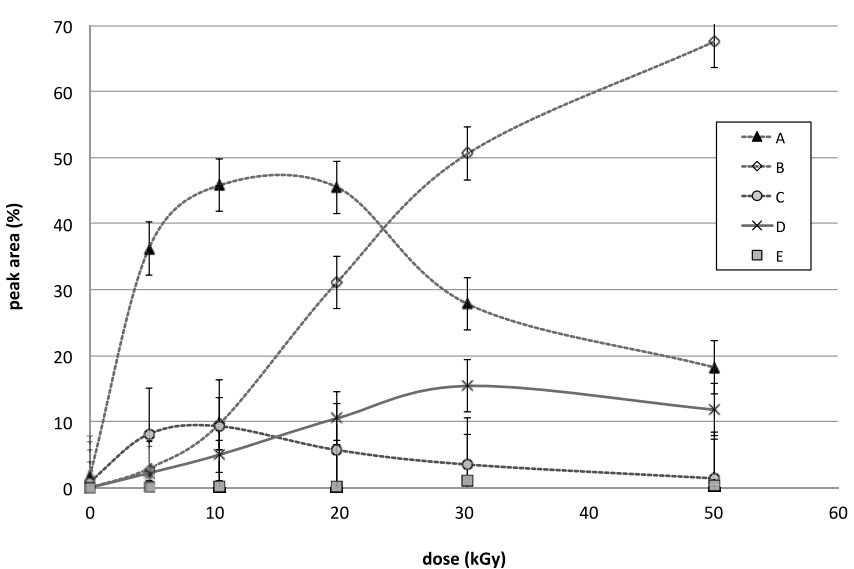

Fig. 9. Growth of degradation products with dose for an irradiated solvent containing C5-BTBP in cyclohexanone that was pre-equilibrated with aqueous phase prior to the irradiation. Percentage is estimated based on the total peak areas determined with HPLC.

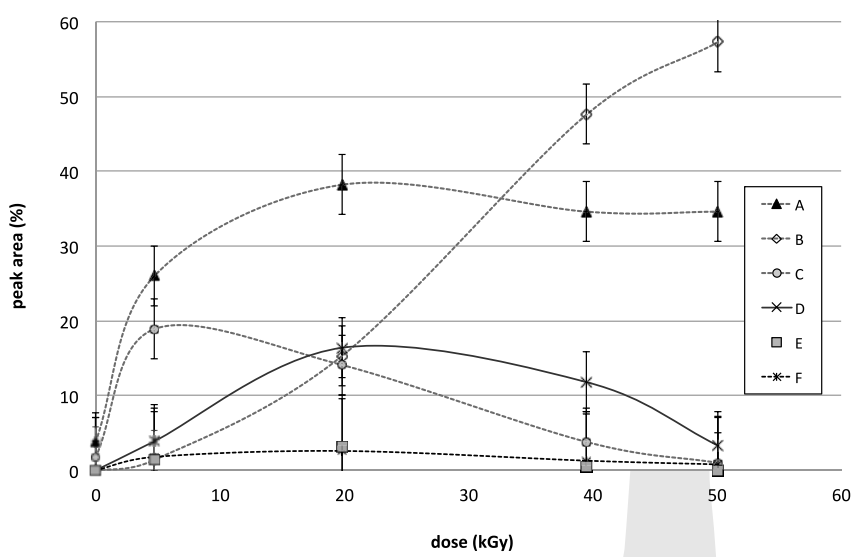

Fig. 10. Growth and distribution of degradation products with dose for an irradiated solvent containing C5-BTBP in cyclohexanone that in contact with an aqueous phase during the irradiation. Percentage is estimated based on the total peak areas determined with HPLC.

Table 1). C represents a product with a structure very similar to product A, probably with a ketone instead of a hydroxyl group attached to the alpha-carbon $(m / z=609)$. Products $\mathrm{D}$ and $\mathrm{E}$ both have structures similar to product B. Either with one hydroxyl and one ketone group attached on the C5chains (product $\mathrm{D}, m / z=625$ ), or with ketone groups on both chains (product $\mathrm{E}, m / z=623$ ). In solvent 3 , an additional degradation product was observed, product $\mathrm{F}$. It is similar to product A but one of the C5-chains has been cut off $(m / z=541)$.

As can be seen from Fig. 9, in the initial stages of degradation of the pre-equilibrated solvent product $\mathrm{A}$ is mainly formed. But its presence is accompanied by formation of product $\mathrm{C}$. The concentrations of $\mathrm{A}$ and $\mathrm{C}$ reach maximum at doses around $10-15 \mathrm{kGy}$, where product $\mathrm{B}$ and D start to increase in concentration. These compounds are thus apparently formed from A and C. After $24 \mathrm{kGy}$ product B is the most abundant product of degradation. A similar pattern is present for the solvent irradiated in the presence of an aqueous phase (Fig. 10), but with product B becoming the main product at around $32 \mathrm{kGy}$. Larger quantities of compound $\mathrm{C}$ is formed already from the initial doses in this solvent, but at the expense of compound $\mathrm{A}$, which reaches a lower

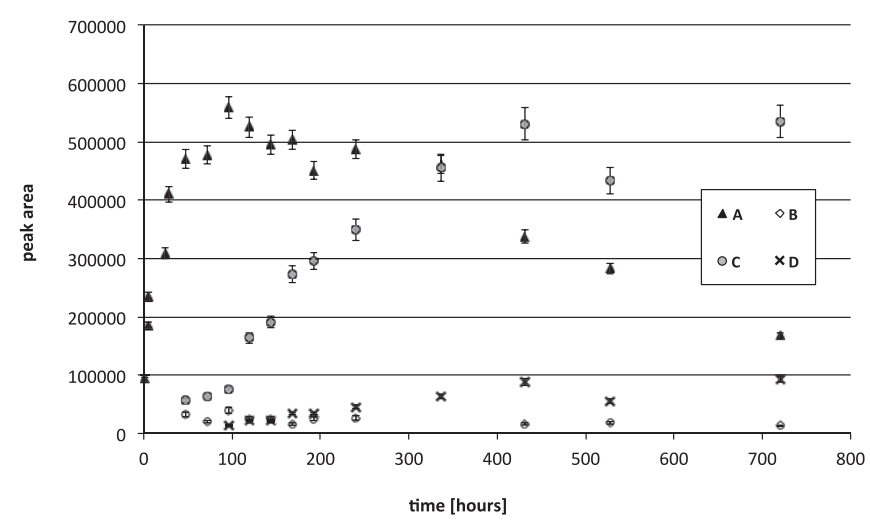

Fig. 11. Peak area of degradation products determined by HPLC in System $X$, in which a solvent containing C5-BTBP in cyclohexanone was subjected to contact with an aqueous phase $\left(0.01 \mathrm{M} \mathrm{HNO}_{3}+\right.$ $0.99 \mathrm{M} \mathrm{NaNO}_{3}$ ). The peak identity was assigned from comparison of the areas on HPLC and LC-MS chromatograms $\left(\mathrm{APCI}^{+}\right.$, ion current detection).

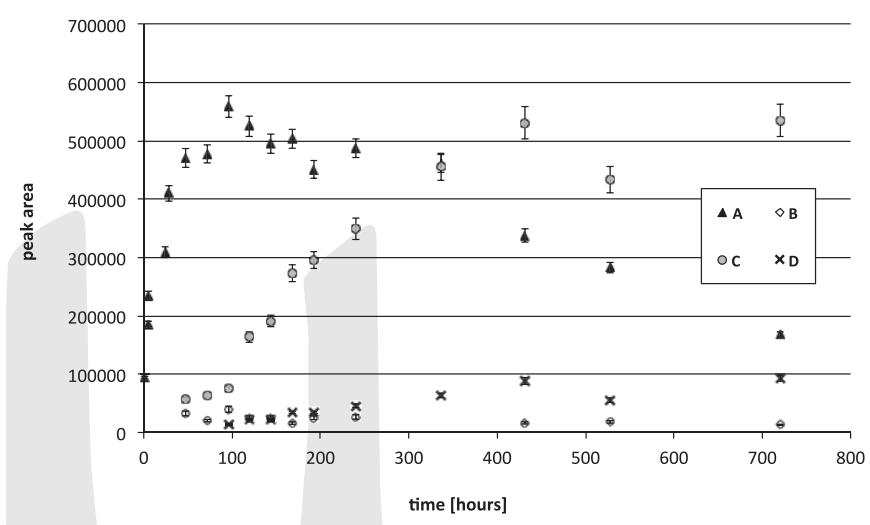

Fig. 12. Peak area of degradation products determined by HPLC in System Y, in which a solvent containing C5-BTBP in cyclohexanone was subjected to contact with water. The peak identity was assigned from comparison of the areas on HPLC and LC-MS chromatograms $\left(\mathrm{APCI}^{+}\right.$, ion current detection).

maximum concentration than in Fig. 9. At higher doses also products $\mathrm{E}$ and $\mathrm{F}$ are formed, and they correspond to deeper stages of oxidation. Product F was only found in Series 3 (Fig. 10).

No C5-BTBP or any identified decomposition products from Table 1 were observed neither by HPLC nor by MS $\left(\mathrm{APCI}^{+}\right)$and $\mathrm{LC}-\mathrm{MS}\left(\mathrm{APCI}^{+}\right.$, ion current detection) in the aqueous phases that had been irradiated in contact with the organic phase (Series 3). Thus, none of the degradation products seem to be soluble in the aqueous phase.

LC-MS analyses confirmed that hydrolysis yields the same C5-BTBP degradation products as radiolysis does (structure A-F in Table 1), a behavior previously reported for other solvents intended for the An/Ln partitioning [24]. A small part of the degradation in the hydrolysis samples is likely caused by ordinary ageing of C5-BTBP, however, as discussed in the "Hydrolysis" section, the major part is a hydrolytic degradation. Although the rates of C5-BTBP decompositions in System X and Y are very similar (Fig. 2), the distribution of the decomposition products varies a lot between the two systems. This is clear from Figs. 11 and 12 where the presence of degradation products A-D is depicted as a function of the contact time for both systems. 
In both systems, the hydroxy derivative A (see Table 1) is the first degradation product formed. The keto derivative $\mathrm{C}$ (see Table 1) is formed in System $\mathrm{X}$ as the second most abundant product, apparently at the expense of compound A, which is further oxidized to compound C. In System Y this compound is formed to much lesser extent and the dihydroxy derivative B (see Table 1) arises here as the second main decomposition product instead. This indicates that the presence of nitrate and nitric acid in the system causes shift to deeper oxidized products. One possible explanation to the deeper oxidation occurring when nitrates are present is the oxidizing nitrogen-centered radicals formed during radiolysis of nitric acid and nitrates (Reacts. R6-R8). In addition, the reducing solvated electron, resulting from water hydrolysis, is scavenged by both an acidic environment (React. R2) and by reaction with nitrate (React. R4).

\section{Conclusion}

In this study we have shown, that C5-BTBP in cyclohexanone is sensitive towards hydrolysis and degrades substantially in contact with water or an aqueous phase containing $0.01 \mathrm{M} \mathrm{HNO}_{3}+0.99 \mathrm{M} \mathrm{NaNO}_{3}$.

Presence of an aqueous phase also plays an important role in degradation of C5-BTBP upon irradiation. Whereas the irradiation of the compound in neat solvent up to $50 \mathrm{kGy}$ led only to slow decrease of concentration, presence of aqueous phase, even that introduced by pre-equilibration, led to rapid decomposition of the extractant with increased dose. Assuming that the aqueous phase can be approximated with pure water, an $8 \mathrm{wt}$. \% dissolution of water into cyclohexanone during pre-equilibration will result in an organic phase containing $8.94 \mathrm{M}$ cyclohexanone and $4.24 \mathrm{M} \mathrm{H}_{2} \mathrm{O}$. This means that the water content is very evident in the preequilibrated aqueous phase. The more obvious decrease in C5-BTBP concentration for solvents that were irradiated in any kind of presence of aqueous solution is not only a result of the hydrolysis but also likely due to the reactive species formed during radiolysis of the nitrate containing aqueous phase. Mincher et al. have recently presented a review dealing with the role of reactive species formed in irradiated organic and aqueous solutions [11]. The highly reactive and oxidizing hydroxyl radical is a result of water hydrolysis and likely initiates most of the reactions leading to degradation of C5-BTBP. Other reactive species formed in water hydrolysis, such as the solvated electron and the hydrogen atom radical, are both scavenged by the presence of oxygen, and also to some extent by nitric acid. The inhibition of these reducing species results in an overall oxidizing environment.

When it comes to the extraction part both $D_{\mathrm{Am}}$ and $\mathrm{SF}_{\mathrm{Am} / \mathrm{Eu}}$ decreased much more for the solvents irradiated with any aqueous phase present. Since extraction of both $\mathrm{Am}$ and Eu still occurs at doses where there is no C5-BTBP left in the solvents (Series 2 and 3), it can be concluded that the degradation products still extract, but with a lower selectivity of Am over Eu. This has been suggested and discussed in a previous paper [9].

Irradiated Series 2 and 3 showed similar degradation products in closely comparable concentrations, suggesting that the same reactions occur, and to the same extent, whether an aqueous phase is present in equal amounts as the organic phase or just dissolved in the organic phase during pre-equilibration.

The same degradation products were found in both the hydrolysis and the radiolysis samples. Thus, the irradiation only seems to speed up the degradation process by generating more energetic particles. From the composition of the degradation products in the different hydrolysis systems it seems that hydrolysis with water leads preferentially to the formation of hydroxy and dihydroxy derivatives A and B. Presence of nitrate ions promotes a deeper oxidation.

Acknowledgment. The authors wish to extend their gratitude to ICHTJ in Warsaw, Poland for assisting with the irradiation process. This work was funded by the European Union Project ACSEPT (Project FP7CP-2007-211 267), the Swedish Nuclear Fuel and Waste Management Co. and Academy of Sciences of the Czech Rep. (Research Plan AV0Z40320502).

\section{References}

1. Madic, C., Hudson, M. J., Liljenzin, J.-O., Glatz, J.-P., Nannicini, R., Facchini, A., Kolarik, Z., Odoj, R.: Prog. Nucl. Energy 40(3-4), 523-526 (2002).

2. Foreman, M., Hudson, M., Geist, A., Madic, C., Weigl, M.: Solvent Extr. Ion Exch. 23(5), 645-662 (2005).

3. Hill, C., Arnaud-Neu, F., Espartero, A. G., Desreux, J.-F., Modolo, G., Bourg, S., Malmbeck, R., Caravaca, C., Harrison, M., De Angelis, G., Uhlir, J., Ouvrier, N., Madic, C.: EUROPART - Final Activity Report, Contract Number: F16W-CT-2003-508 854 (2007).

4. Ekberg, C., Fermvik, A., Retegan, T., Skarnemark, G., Foreman, M. R. S., Hudson, M. J., Englund, S., Nilsson, M.: Radiochim. Acta 96(4/5), 225-233 (2008).

5. Nilsson, M., Andersson, S., Drouet, F., Ekberg, C., Foreman, M., Hudson, M., Liljenzin, J-O., Magnusson, D., Skarnemark, G.: Solv. Extr. Ion Exch. 24(3), 299-318 (2006).

6. Foreman, M. R. S., Hudson, M. J., Drew, M. G. B., Hill, C., Madic, C.: Dalton Trans. 1645-1653 (2006).

7. Retegan, T., Ekberg, C., Englund, S., Fermvik, A., Foreman, M. R. S., Skarnemark, G.: Radiochim. Acta 95(11), 637-642 (2007).

8. Fermvik, A., Berthon, L., Ekberg, C., Englund, S., Retegan, T., Zorz, N.: Dalton Trans. 6421-6430 (2009).

9. Fermvik, A., Grüner, B., Kvíčalová, M., Ekberg, C.: Radiochim. Acta 99, 113-119 (2011).

10. Buxton, G. V., Greenstock, C. L., Helman, W. P., Ross, A. B.: J. Phys. Chem. Ref. Data 17(2), 513-886 (1988).

11. Mincher, B. J., Mezyk, S. P.: Radiochim. Acta 97, 519-534 (2009).

12. Gordon, S., Hart, E. J., Thomas, J. K.: J. Phys. Chem. 68(5) 1262-1264 (1964).

13. Katsumura, Y., Jiang, P. Y., Nagaishi, R., Oishi, T., Ishigure, K., Yoshida, Y.:, J. Phys. Chem. 95(11), 4435-4439 (1991).

14. Cook, A. R., Dimitrijevic, N., Dreyfus, B. W., Meisel, D., Curtiss, L. A., Camaioni, D. M.: J. Phys. Chem. A 105, 3568-3666 (2001).

15. Mincher, B. J., Modolo, G., Mezyk, S. P.: Solv. Extr. Ion Exch. 27, 1-25 (2009)

16. Fermvik, A.: The Effect of Radiolysis of BTBP Type Molecules on Distribution Ratios. Licentiate Thesis, Chalmers University of Technology, Gothenburg (2008).

17. Aneheim, E., Ekberg, C., Fermvik, A., Foreman, M., Nästrén, C., Retegan, T., Skarnemark, G.: Partitioning and Transmutation Annual Report 2008, Swedish Nuclear Fuel and Waste Management Co., SKB Report R-09-03 (2009).

18. Marcus, Y.: Principles of Solubility and Solutions. In: Solvent Extraction Principles and Practice. Chap. 2, $2^{\text {nd }}$ Edn. (Rydberg, J., Cox, M., Musikas, C., Choppin, G. R., eds.) Marcel Dekker Inc., New York (2004). 
19. Fermvik, A., Ekberg, C., Foreman, M. R. S., Retegan, T., Skarnemark, G.: Proceedings of ISEC 2008, Tucson, AZ, 15-19 September (2008), Vol. 1, pp. 551-556.

20. Choppin, G., Liljenzin, J.-O., Rydberg, J.: Radiochemistry and Nuclear Chemistry. $3^{\text {rd }}$ Edn., Butterworth-Heinemann, Oxford (2002), Chap. 7, pp. 170-172.

21. Hill, C., Berthon, L., Bros, P., Dancausse, J. P., Guillaneux, D.: SANEX-BTP process development studies. $7^{\text {th }}$ Information Exchange Meeting on Actinide and Fission Product Partitioning and
Transmutation, Jeju, Republic of Korea, 14-16 October (2002), Paper S2-19, pp. 453-461.

22. Retegan, T., Berthon, L., Ekberg, C., Fermvik, A., Skarnemark, G., Zorz, N.: Solv. Extr. Ion Exch. 27(5), 663-682 (2009).

23. Magnusson, D., Christiansen, B., Malmbeck, R., Glatz, J.-P.: Radiochim. Acta 97(9), 497-502 (2009).

24. Modolo, G., Seekamp, S.: Solv. Extr. Ion Exch. 20(2), 195-210 (2002). 